Fecha de recepción: mayo 2014

Fecha de aceptación: mayo 2015

Versión final: julio 2016

\section{Cuerpo y tiempo}

Leonardo Garabieta *

Resumen: “(. . .) si escapa al tiempo, ¿a que registro del orden de las cosas pertenece el deseo indestructible?"

Interesante frase que sostiene Lacan, pues ¿que es una cosa sino lo que dura idéntico por un tiempo? Sostiene Borges que la identidad humana depende de la memoria y que la memoria depende de considerar al tiempo como una secuencia. ¿¿Será realmente así? ¿Qué sucede pues con nuestros cuerpos, con los que cargamos cada día y todo el día y con aquellos cuerpos que creamos? ¿Qué será de la obra que se encuentra frente a mí? Preguntas, muchas más que respuestas. De eso se trata pues, de reflexionar sobre nosotros, nuestras obras y el tiempo.

Palabras clave: arquitectura - cuerpo - diseño - recorrido - tiempo - vida.

[Resúmenes en inglés y portugués en la página 201]

${ }^{(*)}$ Arquitecto. Urbanista. Administrador de Empresas. Master en Política Económica Internacional. Master en Programación Neurolinguística. Profesor de la Universidad de Palermo en el Departamento de Diseño de Espacios de la Facultad de Diseño y Comunicación. Es docente en diversas instituciones del país. Es profesor invitado de la Universidad de París II (Francia), Universidad de Firenze (Italia), Universidad de El Cairo (Egipto), Universidad de Damasco (Siria), Universidad de Nueva Delhi (India).

“. . si escapa al tiempo, ¿a que registro del orden de las cosas pertenece el deseo indestructible?"

Interesante frase que sostiene Lacan, pues ¿que es una cosa sino lo que dura idéntico por un tiempo? Desde ya la primera pregunta que viene a la mente es ¿cuánto tiempo? Realmente es difícil saber a ciencia cierta cuanto es mucho tiempo y cuanto es poco, desde ya que esto sucede también con otras magnitudes como la distancia, el espacio; en ciertas ocasiones cien metros es poco menos que el infinito y en otras mil kilómetros es muy cerca. Pero volvamos a lo nuestro, el tiempo, sostiene Borges que la identidad humana depende de la memoria y que la memoria depende de considerar al tiempo como una secuencia. ¿Será realmente así? Para la postura judeo-cristiana el tiempo es lineal, consta de un principio, un recorrido y un final. Pero esta es solo una posición, una manera de entender el tema. Para otros el tiempo responde al modelo heraclitano, circular, sin principio ni fin, un eterno volver para comenzar de nuevo un ciclo sin fin. 
¿Qué sucede pues con nuestros cuerpos, con los que cargamos cada día y todo el día y con aquellos cuerpos que creamos? ¿Qué será de la obra que se encuentra frente a mí? Preguntas, muchas más que respuestas. De eso se trata pues, de reflexionar sobre nosotros, nuestras obras y el tiempo.

El homo sapiens es un hacedor innato. Desde su origen en el planeta no ha dejado jamás de crear y aún en algunas etapas donde pareciera que este espíritu creador se tomó un descanso, cuando uno profundiza el estudio, notará que no es así, siempre el humano va por más. El camino siempre es hacia adelante. Quizás sea ese el verdadero sentido humano. Pero ese adelante es fundamentalmente en la dimensión temporal, adelante es mañana, el futuro.

Decíamos líneas atrás reflexionar. También sobre el autor y la obra dentro de la magnitud temporal. Aunque parezca absurdo, en la sinusoide de la historia de la humanidad, hay períodos donde el binomio creador-resultado se pierde por centurias por caminos complejos. Veamos, si se le pregunta a la gente quienes son-por ejemplo- los autores de tal o cual catedral medieval, seguramente no sabrán quienes fueron las mentes que las crearon o las manos que las erigieron, sin embargo todos o al menos la mayoría conocen a Notre Dame de Paris o un sin número de catedrales góticas, abadías románicas o castillos del medioevo. Pareciera que esa etapa de la historia de la Edad Media dejo como legado a sus magníficas obras pero en el anonimato a la mayoría de sus autores.

Por el contrario, si nos situamos en el renacimiento, los hombres, es decir los grandes maestros, opacan a sus obras. Es difícil que los no especialistas sobre el particular, conozcan más de tres o cuatro obras de Miguel Ángel, Leonardo, Donatello o Ghiberti, sin embargo la mayoría si conoce bien a estos genios del arte. Por supuesto podríamos dar ejemplos en diferentes períodos históricos a lo largo y ancho del planeta.

¿Qué sucede pues?

Este fenómeno de discernir entre autor y obra, en síntesis, entre guionista y resultado, ha ido oscilando desde el origen del homo sapiens, y el por qué hay que encontrarlo en el tiempo, y por consiguiente en el espacio en que se produce el hecho.

Hay momentos, como el humanismo donde aquella frase, more humano, resalta al hombre sobre los resultados que pudiera producir. Es el autor, el diseñador quien se perpetúa, las obras son el resultado de ese genio. De hecho conocemos el nombre del primer gran diseñador de la historia, Imhotep, el constructor del gran complejo de Sakkara para el rey Zoser de la tercer dinastía egipcia, tal fue el reconocimiento de Imhotep que fue ascendido a la categoría de dios. El otro gran diseñador fue el mítico Dédalo, el planificador del asombroso laberinto de Cnosos, para ser habitado por el minotauro. No fue tarea menor la de Teseo, encontrar a la bestia, darle muerte y quizás lo más difícil, encontrar el camino de salida, claro la historia hubiera sido otra sin el hilo de Ariadna.

En otros momentos y lugares, la persona queda relegada frente a la obra. Siglos enteros parecen desconocer a aquellos creadores que levantaron obras majestuosas. Cuantos poemas que hemos estudiado en nuestras escuelas eran anónimos. Cuantas obras que recorremos sin tener datos de sus hacedores o simplemente de las mentes que las pensaron.

Hasta podríamos hacer una analogía entre abstracción y realismo. Hubo períodos, algunos relativamente largos, donde el arte, cualquiera fuera sus manifestaciones fue bien realista: el paleolítico, el del imperio romano, la escultura gótica. Otros momentos el abstraccionismo llevo la delantera: el neolítico, el románico, el cubismo, el surrealismo y todo 
el arte musulmán. Por supuesto esto es de una síntesis extrema, pero es solo para ejemplificar. Desde ya que hubo períodos -quizás los más extensos- donde los que primó fue un eclecticismo donde convivieron diferentes estilos y movimientos. Nuestro tiempo es fiel representante de ello.

Nuevamente más preguntas: ¿debemos entonces siempre que analicemos una obra de arte, cine, diseño, arquitectura, comenzar por colocarlo dentro de su contexto histórico? La respuesta es sumamente sencilla: SI. Todo fenómeno, aún si no fuera obra humana, solo puede ser comprendido y por consiguiente analizado dentro de coordenadas tempo-espaciales. De nos ser así, ¿dónde emplazaríamos el hecho? ¿Sobre qué campo epistemológico podríamos comenzar a discutir? Desde el Big Bang, pasando por los dinosaurios y hasta el último Ipad, todo se produce en las mencionadas coordenadas.

Las cosas, los hechos, los hombres, son solo en un lugar y en un espacio, como decía el poeta, no hay otro tiempo que el que nos ha tocado, y en ese tiempo nos haremos como individuos, como sociedad y de allí saldrán nuestras obras. Algunas se extinguirán dentro del tiempo en que nacieron, otras perdurarán en algunos casos por centurias o milenios. Son muy ejemplificante aquellas palabras del historiador Abu Salif ...todo teme al tiempo y el tiempo a las pirámides (...).

La eterna relación texto-contexto, lo producido y el donde y cuando se produce. La descontextualización de la obra es un error bastante recurrente en el cual suelen caer algunos críticos. La cosa es siempre en un lugar y tiempo, por ejemplo un tipología dórica hace veinticinco siglos atrás en la acrópolis de Atenas era un templo. Esa misma tipología en nuestros días en cualquier ciudad moderna puede ser sede de una universidad, una entidad bancaria o albergar cualquier otra función.

El hombre es un ser social e histórico, pero no nace social e histórico, se hace social e histórico. Y allí yace lo importante, se hace, y esto sucede en un contexto tempo-espacial. Y este contexto implica todas las pautas culturales de su tiempo y de su lugar.

En este hacerse, el hombre genera obras de todo tipo y no sabe a priori cual será el período de vida de esas obras. Va de suyo que tampoco sabrá sobre su propio tiempo. ¿Cuánto tiempo puede el resultado sobrevivir al autor? ¿Qué impacto causará aquello sobre las generaciones futuras?

Nuestro tema hoy es el tiempo y como en ese devenir se acomodan las obras que los humanos vamos realizando. ¿Qué hace que tal arquitectura, música, pintura o lo que fuera, se proyecte hacia el futuro, hasta en algunos casos transformarse en paradigmas?

¿Por qué lo greco-latino sobrevivió siglos encontrándose hoy presente en la pos modernidad, mientras que otras filosofías y tendencias del arte simplemente se desvanecieron en la historia? ¿Por qué decenas de lenguas desaparecen año a año del planeta mientras otras crecen?

Pero volvamos por un instante a ese hombre que se hace. Ese hombre- usted, yo- se proyecta, trasciende su hoy, y en este futuro que no existe pero hay que hacer, comienza la angustia que implica en parte superar el hoy. En el fondo todos queremos que nuestras obras duren mucho: hijos, cuadros, música. En síntesis queremos futuro. Que nuestras obras logren la eternidad. Buen momento para recordar como se refieren algunos pensadores sobre el particular. 
Steven Hawking, propone en la teoría del todo, que la mecánica cuántica y la relatividad general, muestran un modelo de universo que por un lado es finito en el espacio y en el tiempo, pero que por otro lado esta exento de bordes, con lo cual no tiene principio ni final definido. No hay frontera entonces entre las magnitudes espacio-tiempo, el universo entonces no sería creado ni destruido.

Para Plotino, enmarcado en el neoplatonismo, la eternidad depende de la plenitud e inmutabilidad del Uno. Algo es eterno cuando no es algo en un momento y otra cosa en otro momento, sino cuando es todo a la vez, indivisiblemente.

Para Espinoza, la eternidad es la existencia misma, ya que esta es la verdad eterna como si se tratara de la esencia.

Platón sostiene que el tiempo es la imagen pasajera de la eternidad, para él lo inmóvil no puede ser ni joven ni viejo.

Parménides sostiene que el ser ya es atributo de la eternidad, mientras que Cicerón ve en el tiempo solo una parte de la eternidad.

Alcanzar la unión del Tao es lo eterno y aunque el cuerpo muere, el Tao nunca pasa. De esta manera presenta Lao Tse a la eternidad.

Para los presentistas, apoyados en la invariancia galileana, solo existe el presente, mientras que para los eternalistas, posición encontrada con la anterior, espacio y tiempo se funden en un todo indiviso y no existen fronteras entre pasado, presente y futuro.

Para Kant, nunca llegaremos a percibir las cosas en si sino las cosas tal y como las percibimos. De allí que llegara a la conclusión de que el tiempo y en espacio no existen fuera de nosotros.

¿Y que piensa usted, lector sobre estos temas? ¿Coincide con algunas de estas posturas, con ninguna, o puede hacer un mix de varias? El ser humano es un animal fascinante, limitado por doquier y siempre tratando de escalar el Olimpo.

El hombre a diferencia del animal, sabe que muere, sabe que al final del camino de la vida se encuentra la oscuridad de la noche y sobre este insondable fondo de tinieblas entreteje su vida, de allí la definición de animal sufriente. Tal vez predestinado, como sugieren algunas religiones y filosofías y nada ni nadie puede escapar del kismet, del destino, como el famoso cuento del esclavo que huye a la mañana de Bagdad por ver a la muerte allí, en la plaza, y que por la noche ésta lo espera en Damasco, hacia donde el propio infeliz había huido para liberarse de la parca.

En el esquema freudiano no existe esclavitud transitoria, no existe liberación definitiva. Todo esclavo es un condenado a cadena perpetua, pues los rebeldes redimen su culpa imponiéndose un régimen represivo más perfecto que en anterior. Como plantea Marcuse, la culpa se redime pecando otra vez, algo así como comer del árbol del conocimiento para poder regresar al estado de inocencia.

En la utopía de Marcuse, hallamos la instauración de la inocencia y el nacimiento del hombre nuevo, de este hombre-dios que supera los contrarios, vence al tiempo y a la muerte, en síntesis quiere escapar del tiempo.

Tratar de que la obra sobreviva al autor es en síntesis eso, escapar al tiempo, traspasar la finitud humana. De hecho es real aquello de que los hombres son juzgados por sus obras, sus legados. Lo notable es que será el futuro quien realizará el balance de lo que sucedió en el pasado, un tiempo porvenir quien juzgara al tiempo que lo antecedió. El tiempo mi- 
diendo al tiempo, suena tragicómico, pero es así, nos movemos en la dimensión temporal y no podemos escapar a ella. Pronosticar, indagar en el futuro, querer saber que sucederá mañana es parte de ser humano. Desde nuestros ancestro recolectores y cazadores pasando por la aurispicia -lectura del hígado que se le quitaba a la víctima aún viva- realizada por los patesis sumerios para leer el futuro, hasta la astrología moderna, siempre hemos querido escrudiñar más allá. Hasta ver el simple pronóstico del tiempo. ¿Lloverá el fin de semana? Desde la magia, las religiones o las ciencias duras, la incógnita del futuro no deja de quitarle sueño al hombre. Por eso de que el hombre es un ser por venir, y claro, que bueno sería saber cómo es ese venir.

Conozco mi presente y mi pasado más allá de las interpretaciones que pueda hacer de ellos y con todas las distorsiones que ello implica. Pero el futuro, es por definición lo inexorable, lo insondable, el gran enigma. En él se verán reflejadas mis decisiones de hoy, él será el espejo donde se reflejarán las acciones realizadas con anterioridad. Todo será en él.

$\mathrm{Y}$ el hecho de que ese desconocido sea el enigma por definición, lo transforma en el generador de angustia.

El mundo del diseño, y aquí me refiero al diseño como una gran carpa que incluye diferentes manifestaciones artísticas y tecnológicas, es claro exponente de lo que venimos desarrollando. Resultados que hacen al hombre más humano, compartiendo aquella visión hegeliana de que cultura es entre otras cosas modificación de la naturaleza. Mediante estos resultados el hombre aprehende y aprende de sus contingencias. Pasa de la simple adaptación al medio, a lograr que ese medio se convierta a su escala, es decir a escala humana, humaniza a su entorno. El hombre como centro como lo planteara Protágoras, al igual que el hombre de Vitrubio o el Modulor de Le Corbusier. Él es la escala del mundo y se proyecta en el tiempo y a través del tiempo.

Estamos en el amanecer de un siglo agitado, en las últimas dos décadas se inventaron más cosas que en toda la historia de la humanidad. Para algunos futurólogos, más del ochenta por ciento de los objetos que usaremos a mediados de la próxima década aún no han sido inventados. ¿Parece ciencia ficción? Pues no, está científicamente comprobado. Y lo maravilloso que el diseño se encuentra absolutamente integrado a este proceso, de hecho el proceso está diseñado.

El planeta tierra seguirá, si no sucede nada extraño, girando sobre su eje y trasladándose con los tiempos que lo viene haciendo desde cuatro mil quinientos millones de años atrás. Sin embargo nuestros tiempos parecen que por momentos se aceleran. Nuestros cuerpos, los que portamos y los que creamos seguirán sus historias, sus ciclos, atados al tiempo.

De jóvenes estudiamos en las escuelas que el tiempo era simplemente el resultado del cociente entre el espacio y la velocidad, sumamente simple. Si debo recorrer cuatrocientos kilómetros y me traslado a cien kilómetros por hora, la ecuación es absurdamente simple, cuatrocientos dividido cien: cuatro horas.

Pero a medida que crecemos nos vamos dando cuenta que esa realidad matemática está lejos de la realidad cotidiana. Primero aquella enseñanza de las escuelas excluía el concepto de aceleración, pero lo más importante, no integró la emocionalidad. Somos sujetos y nuestra visión del mundo es altamente subjetiva, como planteaba Shakespeare, que es la realidad sino aquello que queramos que fuera. Somos unidades bio-psico-sociales, en síntesis individuos que filtramos toda la información que nos llega a través de nuestros 
sentidos y emociones. Veamos.

Una hora no es simplemente una hora, es un recipiente lleno de perfumes, de sonidos, de proyectos y de clima. Lo que llamamos realidad es una cierta relación entre esas relaciones y recuerdos que nos circundan simultáneamente, relación única que el autor debe encontrar para encadenar para siempre su discurso. Entendemos como discurso toda enunciación que supone un hablante y un oyente y que el primero intenta influir sobre el otro.

De hecho, el diseño, los cuerpos salidos a partir de él ¿no influyen acaso sobre un sinnúmero de oyentes a través del tiempo?

¿Pero, de qué tiempo hablamos?

Los griegos tenían dos personajes en su mitología que explicaban claramente este tema. El primero es Cronos, el tiempo mensurable, ese que hace que todos los minutos tengan sesenta segundos, siempre sesenta segundos, es el tiempo que mido con mi reloj, con el calendario, siguiendo los ciclos astronómicos. Cronos, quien todo lo devora, quien se come a sus propios hijos, con quien habrá de usar la astucia para poder salvar al mismo Zeus de ser engullido por su padre. El implacable Cronos. Pero hay otro tiempo, Kairos, el tiempo sensible, emotivo, aquel que hace que un minuto parezca un año y una hora un segundo, es el tiempo que dura un beso, la contemplación de una obra, ... en síntesis el tiempo sin tiempo, algo así como adentrarse en una ucronía.

Kairos es el tiempo emocional, el de los sueños, de las fantasías, de los anhelos, el de la vida vivida con mayúsculas. Es el tiempo que se siente en las tripas y nos hace vibrar.

Y de esa manera vivimos en dos planos alternativos, el del tiempo mensurable y programado, como decía Borges, 1964, las tardes a las tardes son todas iguales a las tardes, y por otro lado el de mi vivencia, que será diferente a la suya a la del otro, será mi tiempo subjetivo, donde estaré inmerso en kairos. Como planteaba Marcel Proust, 1927 “... mi alma nace todos los días, se sacude de cualquier peso que la quiera domesticar y renace para volver a renacer". $\mathrm{O}$ a su famoso momento que al saborear una magdalena le viene a la mente una serie de recuerdos ya olvidados.

¿No le ha pasado acaso querido lector que un aroma, una melodía, una situación lo remonta años atrás? Allí volvió Kairos.

Como planteaba el padre del existencialismo, Martín Heidegger, el ser es temporalidad y la muerte es quien condiciona esa temporalidad, de allí que a diferencia de otros posibles que puedo realizar, no podré jamás decir me he muerto. No obstante el hombre es un ser arrojado a lo ilimitado, al infinito, a la intemporalidad, aunque suene extraño, arrojado al futuro, por consiguiente a lo impredecible. El hombre marcha hacia él, más allá de lo rectilíneo o zigzagueante que pueda ser su recorrido. Va de suyo que sus obras van con él, muchas veces más allá que él.

Dice Sófocles en Antígona:. . . muchas cosas son admirables, pero ninguna como el hombre. Es él quien al otro lado del espumante mar se traslada llevado por el impetuoso viento a través de las olas que braman, a lo largo del tiempo. Esta frase fue escrita hace dos mil quinientos años, en época de Pericles, precisamente cuando la Acrópolis de Atenas se reconstruía totalmente con materiales duraderos para soportar el desgaste del tiempo, un legado para el futuro, obras realizadas para ir más allá de los tiempos. Recordemos que cuando contemplamos el Partenón, allí en el mismo emplazamiento se encontraba el Hecatompedom, el templo de los cien pasos, construido en gran parte en madera e incen- 
diado en las guerras contra los persas. Trascender el tiempo y sus vicisitudes necesitaba de diseño y materiales nobles, y desde entonces el mármol de la mano de Fidias lo logró. El hombre necesita para vivir, al igual que agua y comida, metas, precisa un para que, algo que esté más allá del hoy. ¿Y por qué todo esto? Porque el humano es el único ser con capacidad de transformar lo sucedido en suceder, de allí que el futuro sea por definición el motor de lo que haga, de lo que diseñe, es el para qué y ese mañana condiciona la aquí y ahora. El porvenir es el repertorio y a la vez el lugar concreto de los sueños. Es el Partenón de mármol.

Pensemos por un instante en los hechos y las obras llevadas a cabo por nuestros ancestros. Siempre fueron en pro del mañana, desde los monumentos funerarios, que en el último de los casos resultan ser obras para la perpetuidad, los templos, el arte, la literatura, la filosofía, absolutamente todo fue concebido para trasvasar el presente.

Aún la estructuras de todas las religiones se proyectan hacia adelante: la tradición hindú con los avatares, supuestamente encarnaciones de lo divino, de allí la espera de Kalki, los budistas esperan al Buda Maitreya, los judíos al Mesías, algunos musulmanes al Madhi y los cristianos la vuelta de Cristo. Por dar solo algunos casos. Sin afirmar ni negar ninguna de estas creencias, todas tienden a trascender el espacio-tiempo.

Esta conciencia se puede entender en términos psicológicos como la búsqueda de lo que Maslow llamó meta valores en la condición corporizada, es decir valores elevados que tiene que ver con el mejoramiento del ser y eso se produce en una dimensión del futuro. Diseño, cuerpo, tiempo hoy en el S XXI. Las nuevas tecnologías en el mundo de la informática que permiten mostrar los diseños de una manera icónica tal que imitan la realidad como antes nunca se pudo lograr, los nuevos materiales y procesos que año a año se incorporan al mercado y una sociedad que en las dos últimas décadas se abrió por completo al mundo del diseño, hizo de éste algo tan complejo y cambiante que lo transformo en uno de los segmentos más fascinantes de la vida cotidiana.

Una sociedad donde pareciera que el tiempo se aceleró, donde lo creado ayer ya es viejo, donde en esta modernidad liquida, parafraseando a Baumann, la basura, lo que se tira es más importante que lo que se adquiere, ya esto mañana ya terminara en el cesto de residuos. ¿Cuál será el tiempo de duración de los cuerpos creados en esta sensación de montaña rusa?

La globalización en todos sus aspectos, obviamente facilito este proceso de integración donde diseñadores de todo el mundo salieron de sus cubículos para formar parte de una matriz general, mucho más grande y fundamentalmente más intercomunicada. Los medios con los que contamos hoy, hubieran parecido ciencia ficción hace solo pocas décadas. Basta con recorrer el mundo por cualquier continente para ver la mano de tal diseñador o tal tendencia más allá de su lugar de nacimiento. En los últimos meses tuve la oportunidad de recorrer centros y facultades de diseño en diferentes países de Europa, África y Asia, y la temática en cuestión se repetía: las obras de tal diseñador -Gheri, Foster, Piano, Hadid, etc- o tal tendencia -minimalismo, high tech, etc- en tal o cual lugar. Algunas reciben serias críticas por su descontextualización respecto al entorno, otras son aceptadas a regañadientes, pero esto llegó para quedarse, al menos por un largo tiempo. De hecho, la historia cuenta con antecedentes más que importantes: el arte greco-budico, es decir la influencia de la herencia de Alejandro en Asia, el arte colonial americano que no es otra cosa que la 
traspolación del barroco a América o los diferentes neos que se produjeron a través de los últimos siglos. Si, ya tuvimos atisbos de globalización, sino simplemente pensemos en el imperio romano o mogol.

Lo que diferencia la globalización actual de las anteriores mundalizaciones, es que antes por muy grande que fuera un imperio con su extensión cultural, siempre fue regional, hoy si es global. Hace solo doscientos años una carreta del alto Perú a Buenos Aires necesitaba casi dos meses para cerrar su travesía. Hoy la información es en tiempo real -palabra que pueden sonar absurdas- , es decir el mensaje, emisor y receptor todo junto en centésimas de segundos. Llegamos a la civilización de los nanosegundos, de los nanomilímetros y otros tantos nanos. Antes impresionaba lo grande, hoy asombra lo pequeño, realmente lo muy pequeño.

Incursionar hoy en el mundo del diseño implica ya no solo reconocer el trípode vitrubiano de la forma-función-estructura, en cada diseño sino que debemos incorporar lo simbólico, lo comunicacional, la sustentabilidad y una larga serie de variables que acompañan al nuevo milenio.

En un mundo donde pareciera que lo único estable es el cambio -y vertiginoso por cierto- el diseño en su concepción mas abarcativa, se fue transformando en algo sumamente dinámico para acompañar ese cambio.

A través de centurias fueron los filósofos quienes se adelantaron a los puntos de inflexión de la historia, quienes percibieron lo que venía, algo así como los futurólogos de sus tiempos. Pareciera que en el presente son los diseñadores quiénes se encuentran delante de los cambios, quienes alertan de los que vendrá. Si realmente fuera así, estamos frente a cambio de paradigmas, cosa no menor en este mundo de cambios.

Hoy el mundo del diseño comenzó a ocupar el espacio de cuestionador y crítico que otrora estuvo reservado a otras disciplinas en todos los quehaceres, dese los más simples y elementales hasta los más sofisticados. Recuerdo aquellos importantes congresos de los 70, a los que concurría, donde conceptos sobre epistemología, comunicación, sustentabilidad, y otros tantos que hoy se encuentran presentes en las aulas y talleres de las carreras de grado, simplemente no existían. Claro usted me podrá decir que tampoco existían los automóviles sin carburador, pero es que de eso se trata, del tiempo y de lo que se suma a través de él. Sin lugar a dudas los nuevos tiempos traen nuevos desafíos, y habrá que estar a sus alturas. La perspectiva del diseñador de hoy es enorme, tiene cabida en cada espacio de la actividad humana, todo lo que nos rodea está diseñado, aún la naturaleza está cada vez más conformada -diseñada- por el hombre. Una responsabilidad mayúscula ya que sería de esperar que los errores fueran cada vez menos y menores.

¿Y usted estimado lector, que opina? ¿Cómo serán los diseños y sus materializaciones en los tiempos que se aproximan? ¿Qué es de esperar de este binomio cuerpo-tiempo? Nuestros cuerpos biológicos, avances científicos mediante, permiten a la medicina prolongar nuestras vidas, un integrante del consejo de ancianos de Atenas en el siglo de oro, hoy sería un joven adulto. Sí, cada vez somos más longevos, la OMS publicó hace tan solo algunas semanas, que hay en el planeta, cientos de personas mayores de cien años.

Como le plantee al principio, preguntas y más preguntas, las respuestas, en el tiempo, es decir en el futuro, mientras tanto nos queda hacernos cargo de nuestros cuerpos y de ir dejando huellas en las arenas del tiempo. 


\section{Bibliografía}

Agulla, J. C. (1994). La experiencia sociológica. Buenos Aires: Ed. Instituto de Derecho Público. Borges, J. L. (1973). Obras completas. Buenos Aires: Ed. Emece.

Garabieta, L. (2012). Los andamios del tiempo. Ed. Nobuko. Argentina.

(2011). Arquitectura Sagrada. Buenos Aires: Ed. Nobuko.

(2006). Más allá del corto plazo. Buenos Aires: Ed. Legar.

(2005). Incertidumbre. Buenos Aires: Ed. de Belgrano.

(2003). Cultura del Malestar. Buenos Aires: Ed. de Belgrano.

(2002). Ucronía. Buenos Aires: Ed. de Belgrano.

Summary: “(...) if it's timeless, to which record in the order of things belongs the indestructible desire?"

In this statement Lacan states that a thing is what lasts the same for a while. Borges argues that human identity depends on memory and memory depends on considering time as a sequence. Is it really so? What happens to our bodies, with the bodies we carry every day and all day long and with those bodies that we create? What will become the work that is in front of me? Much more questions than answers in this article where we'll try to reflect about us, about our works and about time.

Keywords: architecture - body - design - life - route - time.

Resumo: O ensaio reflete sobre as obras humanas e o tempo. O escritor Jorge Luis Borges disse que a identidade humana depende da memória, e que a memória depende de considerar ao tempo como uma seqüência. A pergunta que surge é que acontece com o corpo que carregamos cada dia e com aqueles que criamos.

Palavras chave: arquitetura - corpo - design - percurso - tempo - vida. 